\title{
Stability of bimaxillary surgery on Class III malocclusion treatment
}

\author{
Fernando Antonio Gonçalves', Vânia Célia Vieira de Siqueira²
}

Objective: To evaluate the stability of bimaxillary surgery in patients with skeletal malocclusion, with the use of rigid internal fixation. Methods: Lateral cephalograms from 20 patients, 11 males and 9 females, mean age of 26 years and 1 month, were evaluated before surgery, immediately post-operative and at least 6 months after surgery. Nineteen cephalometric measurements were evaluated, and the results were statistically analyzed by means of the Student's $t$ test and the Kruskal-Wallis test. Results: The Le Fort I maxillary advancement surgery showed almost no relapse. There was lack of stability of mandibular setback, with relapse of $37.33 \%$ on point B, due to counterclockwise rotation of the mandible between post-operative periods, occurred by better intercuspation after surgery and muscle adaptation. The results showed the same tendencies for both genders. Conclusion: It was concluded that on the bimaxillary surgery treatment of Class III malocclusion, the maxillary surgery was very stable, but the mandibular setback recurred. No statistical differences were found in surgical stability between genders.

Keywords: Angle Class III malocclusion. Osteotomy. Le Fort osteotomy.

Objetivo: avaliar a estabilidade da cirurgia combinada de maxila e mandíbula em pacientes com má oclusão esquelética de Classe III com a utilização de fixação interna rígida. Métodos: utilizaram-se telerradiografias obtidas em norma lateral de 20 pacientes, sendo 11 do sexo masculino e 9 do feminino, com média de idade de 26 anos e 1 mês, avaliados antes da cirurgia, no pós-operatório imediato e no mínimo 6 meses após a cirurgia. Avaliaram-se dezenove grandezas cefalométricas e os resultados foram analisados estatisticamente por meio do teste $t$ de Student e da análise de Kruskal-Wallis. Resultados: a cirurgia de avanço maxilar praticamente não apresentou recidiva. Ocorreu perda de estabilidade do recuo mandibular, com recidiva de $37,33 \%$ no ponto B, devido ao giro anti-horário da mandíbula entre os períodos pós-operatórios, ocorrido pela melhor intercuspidação pós-cirúrgica e adaptação muscular. Os resultados apresentaram as mesmas tendências para ambos os sexos. Conclusão: concluiu-se que no tratamento cirúrgico combinado da má oclusão de Classe III, o procedimento realizado na maxila mostrou-se muito estável, já o recuo mandibular apresentou recidiva. Não evidenciou-se diferenças estatísticas na estabilidade cirúrgica entre os sexos.

Palavras-chave: Má oclusão de Angle Classe III. Osteotomia. Osteotomia de Le Fort.

${ }^{1} \mathrm{MSc}, \mathrm{PhD}$ in Orthodontics, FOP-UNICAMP. Professor of Graduation and Specialization in Orthodontics, FUNEC, Santa Fé do Sul.

${ }^{2} \mathrm{PhD}$ in Orthodontics and Public Health Dentistry, USP. Professor of Orthodontics, FOP/UNICAMP.

» Patients displayed in this article previously approved the use of their facial and intraoral photographs.

» The author reports no commercial, proprietary or financial interest in the products or companies described in this article.
How to cite this article: Gonçalves FA, Siqueira VCV. Stability of bimaxillary surgery on Class III malocclusion treatment. Dental Press J Orthod. 2012 Nov-Dec;17(6):41-51.

Submitted: November 6, 2008 - Revised and accepted: February 9, 2010

Contact address: Fernando Antonio Gonçalves

Av. Santo Antonio, 545 - Vila Xavier - Araraquara/SP - Brazil

CEP: 14810-115 - E-mail: dfgodontologia@terra.com.br 


\section{INTRODUCTION AND LITERATURE REVIEW}

The orthognathic surgery was introduced in Brazil in the 80's, being most frequently applied in the mandible and using intermaxillary fixation with steel wires. With the improvement of surgical techniques and the use of rigid internal fixation, this treatment obtained wider acceptance, and with the increasing number of surgeons and medical centers, it has also become more accessible.

The orthodontic-surgical treatment involves interaction of several professionals. A patient with skeletal malocclusion develops dental compensations, precluding or restricting the surgical correction. ${ }^{15}$ For this reason, the pre-surgical orthodontic treatment must set the teeth in their bone bases, eliminating the dental compensations, allowing a more harmonious face and functional improvement with surgery, leading to more predictable and stable results.

The facial analysis constitutes an important factor on the diagnosis and surgical planning, assisting in defining the surgical moves to be performed, because it is often indicated the bimaxillary surgery to avoid major isolated surgical movements since they provide higher risk of relapse. ${ }^{21}$

The most stable orthognathic procedure with less than $10 \%$ of the possibility of post-operative changes from 2 to $4 \mathrm{~mm}$ is the jaw impaction, followed by mandibular advance. The advancement of the jaw is in second category, with possibility of $20 \%$ or less from 2 to $4 \mathrm{~mm}$ of relapse. To achieve an acceptable stability in bimaxillary surgery, the rigid internal fixation becomes imperative. Three procedures are classified as problematic with the possibility of 40 to $50 \%$ of relapse from 2 to $4 \mathrm{~mm}$ : The mandibular setback, inferior repositioning of the maxilla and maxillary expansion. ${ }^{2}$

The post-surgical stability has improved with the use of internal fixation because it accelerates the bone repair, allows the immediate restoration of the function, decreases complications from maxillomandibular fixation, facilitates the acceptance of treatment, and facilitates the patient's oral hygiene and diet. ${ }^{15}$

Several factors can affect the stability of orthognathic surgery: The condylar displacement, presurgical orthodontics poorly performed, the type and duration of maxillomandibular fixation, the direction of surgical movement, stretching the suprahyoid muscles, increase of the posterior facial height, multiple surgical segments. ${ }^{27}$

The altered activity and the failure of masticatory muscles in adaptation to the new position may contribute to skeletal relapse in mandibular setbacks, as well as continued condylar growth. ${ }^{9}$ Different results are found in literature about the stability of the mandibular sagittal osteotomy for correction of Class III malocclusion, and most relapses occur within six months after surgery. ${ }^{17}$

The pre- and post-orthodontic surgery poorly performed, the interference of the nasal septum, scar retraction, mobilization or inadequate fixation, the quality of results of occlusion and the non-passive positioning of the maxilla may affect the stability of maxillary advancement. ${ }^{19}$

After 1985, the number of bimaxillary surgery for the correction of Class III malocclusion increased significantly, and yet there are few documented studies about the stability of this procedure using rigid internal fixation. ${ }^{19}$

There are controversies in several studies in literature, about the stability of the isolated surgery of the maxilla and mandible when compared with the stability of bimaxillary surgical procedures, and the fixation methods used as well as other factors that influence the stability. ${ }^{18,26}$ Therefore, many variables are correlated with orthodontic-surgical treatment, and since lately this procedure is performed more often, new studies are important for a better scientific basis. Thus, it was considered important to assess the stability and sexual dimorphism in patients with skeletal Class III malocclusion that underwent bimaxillary surgery, with the use of rigid internal fixation (RIF).

\section{MATERIAL AND METHODS}

The present study was approved by the Ethics in Research Committee of the Faculty of Dentistry of Piracicaba, State University of Campinas, under protocol 013/2003.

Twenty orthodontic records of patients were used from CEDEFACE (Center for Research and Treatment of Orofacial Deformities, Araraquara, SP) files: 11 males and 9 females, ages between 17 and 35 years old, and mean age of 26 years and 1 month. 
It was used the following inclusion criteria to select the sample:

1. Cephalometric radiographs from CEDEFACE files of adult patients with Angle Class III malocclusion.

2. All patients followed the CEDEFACE treatment protocol, consisting of evaluation and participation in pre- and post-surgical of several professionals: Audiologists, physical therapists, otolaryngologists, orthodontists, surgeons, among others.

3. Absence of local and/or general contraindication for the orthognathic surgery.

4. Pre-surgical orthodontic treatment to properly coordinate the dental arches and eliminate dental compensations, improving the positioning of the teeth on their bone bases, and in postsurgical phase for refinement of the occlusion.

5. Surgical treatment consisting of: a) LeFort I osteotomy on the maxilla, followed by rigid internal fixation with miniplates and titanium screws $2.0 \mathrm{~mm}$ monocortical system, Prolig brand, positioned in canines and zygomatic pillars (Fig 1); b) bilateral sagittal osteotomy of the mandibular ramus for mandibular setback, followed by rigid internal fixation with three bicortical positional screws, system $2.0 \mathrm{~mm}$, brand Synthes (Figs 2 and 3).

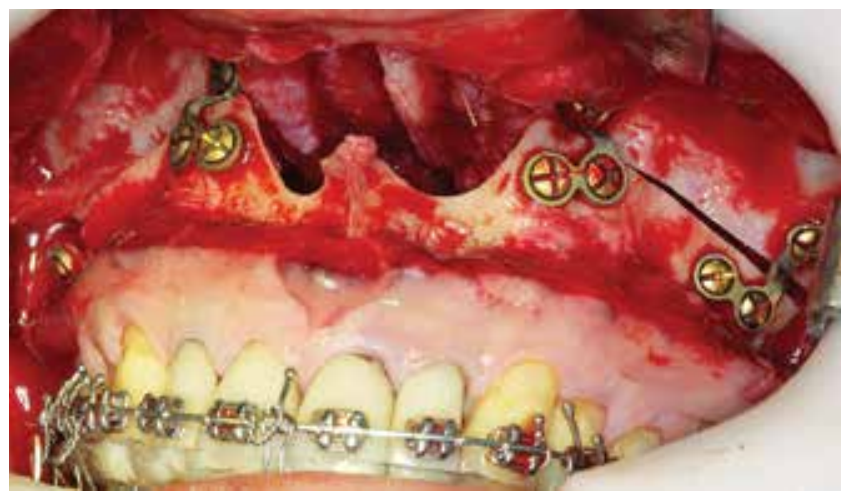

Figure 1 - Le Fort I osteotomy with RIF.
6. All patients were operated by the same surgical team.

7. No other craniofacial deformities, cleft lip/ palate or syndromes.

8. Cephalometric radiographs were obtained in the preoperative period $\left(\mathrm{T}_{0}\right)$, the immediate post-operative period, approximately one week after surgery $\left(\mathrm{T}_{1}\right)$ and post-operative period with at least 6 months after treatment surgery $\left(\mathrm{T}_{2}\right)$.

\section{Cephalometric method}

For the cephalometric evaluation it were used some measurements from the McNamara's ${ }^{16}$ analysis, and the cephalometric tracings were based on the studies of Burstone, ${ }^{5}$ Proffit, ${ }^{20}$ Franco, ${ }^{9}$ Gassmann, ${ }^{10}$ Law, ${ }^{15}$ Ayoubad, ${ }^{1}$ who used two reference lines, one vertical and the other one horizontal (Table 1).

The minimum assessed post-operative period was 6 months and the maximum was 7 years and 5 months, with an average of 2 years and 3 months. Radiographs were obtained in the same equipment, and conducted by the Department of Radiology, Faculty of Dentistry of Araraquara, São Paulo State University (UNESP).

There were two cephalograms of each radiograph, traced by a single researcher, and therefore all measurements were repeated using the mean for the statistical analysis, as recommended by Houston ${ }^{13}$ in 1983.

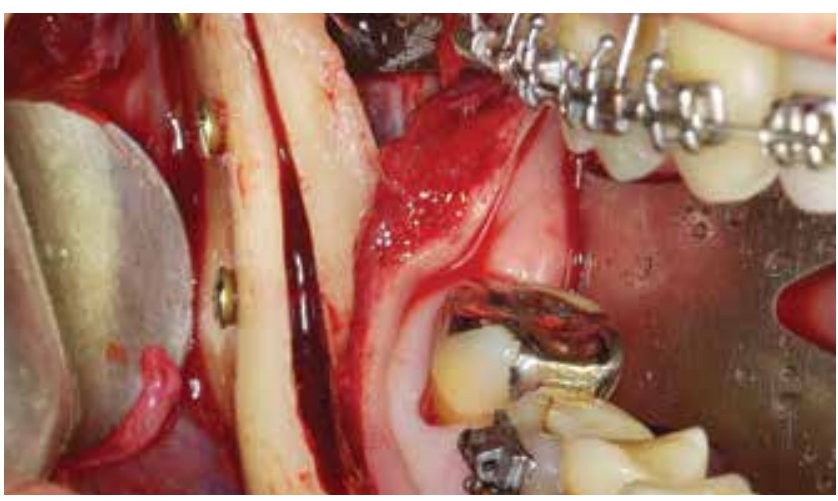

Figure 2 - Sagittal mandibular osteotomy with RIF.

Table 1 - Reference lines used in the study.

\begin{tabular}{cc} 
Lines & Determination \\
\hline Saddle-nasion line $(\mathrm{SN})$ & Line through the points $\mathrm{S}$ and $\mathrm{N}$ \\
Horizontal Reference $(\mathrm{HRL})$ & Line obtained at $-7^{\circ}$ of $\mathrm{S}-\mathrm{N}$ line, starting from the saddle point \\
Vertical Reference Line $(\mathrm{VRL})$ & Line traced perpendicularly to the horizontal reference line, starting from the Saddle point \\
\hline
\end{tabular}


Measurements were done with the aid of a drypoint compass and transferred with a digital caliper.

It were used the following cephalometric points: Sella turcica (S), nasion (N), subspinale (A), supramentale (B), anterior nasal spine (ANS), posterior nasal spine (PNS), pogonion (Pg), joint ( $\mathrm{Ar}$ ), posterior ramus $(\mathrm{PR})$, mentalis $(\mathrm{Me})$, gnathion $(\mathrm{Gn})$, condyle (Co). It is important to mention that the PR point was chosen due to its location, because it is not influenced by osteotomy, making it easier to point it out.

The distance in millimeters from each point was measured perpendicularly to the reference lines, thus, it was obtained a horizontal and a vertical extent from each point related to them (Fig 4).

For a better evaluation and interpretation of the results, five measurements were used from the cephalometric McNamara's analysis: ${ }^{16}$ Nperp-A, NperpPg, Co A, Co-Gn, ANS-Me.

After obtaining the distances from each point related to the reference lines, it was calculated the difference between the distances on cephalograms $\mathrm{T}_{0}, \mathrm{~T}_{1}$ and $\mathrm{T}_{2}$. Thus, the differences between the measurements regarding the points $\mathrm{T}_{0}$ and $\mathrm{T}_{1}$, revealed the amount of the surgical movement, and the measurement differences between $\mathrm{T}_{1}$ and $\mathrm{T}_{2}$ quantified the post-operative changes for each point.

\section{Statistical method}

The following variables were studied from the Horizontal Reference Line (HRL): ANS, HRL-A, HRLPNS, HRL-Ar, HRL-PR, HRL-Pg, HRL-B. And from the Vertical Reference Line (VRL): ANS, VRL-A, VRLPNS, VRL-Ar, VRL-PR, VRL-Pg, VRL-B, Co-A, Co-Gn, Nperp-A, Nperp-Pg, ANS-Me, being factors of study the surgical period and the patient's gender.

It was carried out a comparison between the two measurements initially obtained from each evaluated measurement using the Student's $t$ test to verify the error in obtaining them.

Statistical analysis of Kruskal-Wallis test, using the statistical program Stat Bio 4.0, was performed to compare the differences between $\mathrm{T}_{1}-\mathrm{T}_{0}$ and $\mathrm{T}_{2}-\mathrm{T}_{1}$, representing the surgical procedures and the postsurgery modification, respectively. It was also noticed the existence of differences in the surgical stability between genders. For all the performed tests, it was considered a significance level of $5 \%$.

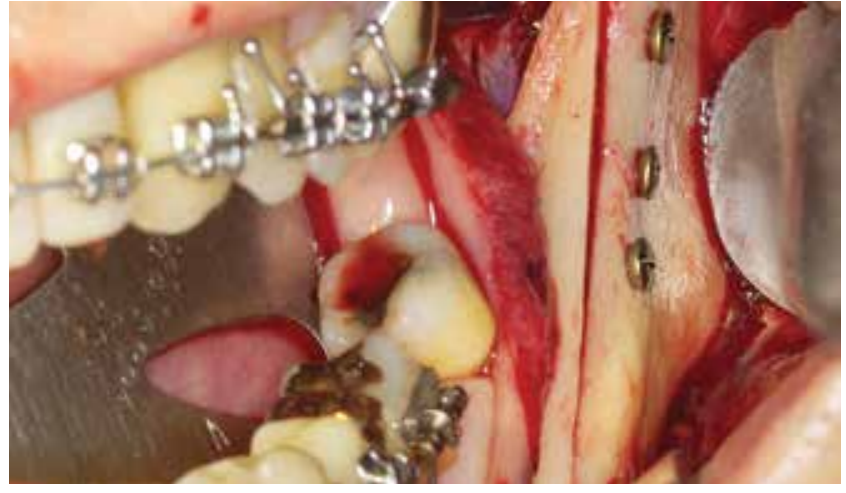

Figure 3 - Sagittal mandibular osteotomy with RIF.

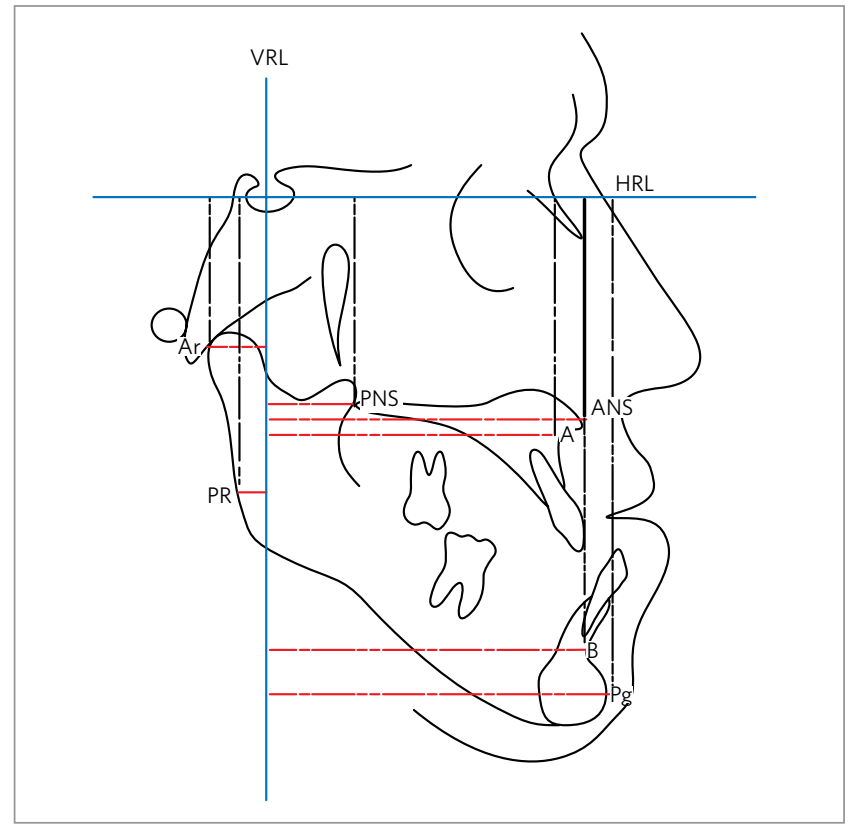

Figure 4 - Vertical and horizontal linear measures used in the study.

\section{RESULTS}

The obtained values were organized in tables and graphs to better evaluate the results (Tables 2, 3, 4, 5, and 6; Figs 5, 6 and 7).

Analyzing the results of the measurements HRLANS, HRL-A and HRL-PNS it was noticed that the maxilla was slightly moved in the vertical direction. Although the obtained values for HRL-A and HRLPNS were statistically significant for the overall averages, these alterations showed no clinical importance.

The measurement HRL-Ar was not statistically significant, unlike the measurement HRL-PR, but since this alteration was very small, it was concluded that there was no alteration in the vertical direction of the Ar and PR points. 
Table 2 - Total mean, means for males and females, standard deviations of the differences $T_{1}-T_{0}$ and $T_{2}-T_{1}$, for measurements HRL-ANS, HRL-A, HRL-PNS and HRL-Ar.

\begin{tabular}{|c|c|c|c|c|c|c|c|c|}
\hline \multirow[b]{2}{*}{ patient } & \multicolumn{2}{|c|}{ HRL-ANS } & \multicolumn{2}{|c|}{ HRL-A } & \multicolumn{2}{|c|}{ HRL-PNS } & \multicolumn{2}{|c|}{ HRL-Ar } \\
\hline & $T_{1}-T_{0}$ & $\mathrm{~T}_{2}-\mathrm{T}_{1}$ & $\mathrm{~T}_{1}-\mathrm{T}_{0}$ & $\mathrm{~T}_{2}-\mathrm{T}_{1}$ & $T_{1}-T_{0}$ & $\mathrm{~T}_{2}-\mathrm{T}_{1}$ & $\mathrm{~T}_{1}-\mathrm{T}_{0}$ & $\mathrm{~T}_{2}-\mathrm{T}_{1}$ \\
\hline $2(F)$ & -0.05 & -1.36 & -0.18 & -1.14 & -0.18 & -1.14 & 0.01 & -0.52 \\
\hline $5(F)$ & -0.05 & 1.18 & -0.2 & 1.27 & -1.53 & 1.14 & -1.74 & -1.22 \\
\hline $7(F)$ & -0.3 & -0.51 & 0.88 & -2.08 & -2.36 & -2.78 & -0.97 & 0.18 \\
\hline $10(F)$ & 0.43 & 1.35 & 1.26 & 0.86 & -0.65 & 1.21 & -0.63 & 0.08 \\
\hline $15(F)$ & -4.63 & 3.52 & -4.4 & 2.46 & -2.46 & 0.3 & 1.08 & -1.73 \\
\hline $17(F)$ & -0.12 & 0.22 & -1.96 & 0.33 & -1.83 & 0.68 & -1.1 & 0.53 \\
\hline $18(F)$ & 1.37 & -1.35 & 3.1 & -2.61 & -0.5 & 0.13 & -0.85 & 0.22 \\
\hline $19(F)$ & 2.19 & -1.35 & 2.53 & -1.64 & -2.68 & 1.33 & -2.94 & -0.72 \\
\hline $20(F)$ & -0.81 & 0.95 & 0.82 & -0.36 & -2.01 & 1.72 & -0.45 & -0.6 \\
\hline$F$ mean & -0.22 & 0.29 & 0.20 & -0.32 & -1.58 & 0.29 & -0.84 & -0.42 \\
\hline $1(M)$ & -1.27 & -0.7 & -0.29 & -0.98 & -1.55 & 0.46 & 1.18 & 0.45 \\
\hline $3(M)$ & -0.64 & -0.89 & -0.89 & -1.25 & -2.72 & -0.23 & 2.27 & -0.37 \\
\hline $4(M)$ & -0.34 & -1.49 & 0.34 & -2.19 & -2.67 & -2.22 & -0.63 & 1.03 \\
\hline $6(M)$ & -3.26 & 1.2 & 2.24 & -0.69 & -1.19 & -2.09 & -0.32 & -2.15 \\
\hline $8(M)$ & -0.65 & 0.94 & 2.46 & 0.31 & -0.49 & 1.02 & 1.22 & 1.76 \\
\hline $9(M)$ & 1.42 & -2.45 & 0.48 & -1.01 & 0.55 & -0.6 & 0.23 & -0.35 \\
\hline $11(M)$ & -3.28 & -1.7 & -0.93 & -2.68 & -2.62 & 0.22 & -0.72 & 1.87 \\
\hline $12(\mathrm{M})$ & 1.22 & 2.96 & 2.95 & 0.92 & -0.43 & 2.06 & 0.73 & 0.48 \\
\hline $13(\mathrm{M})$ & 2.02 & 0.07 & 2.58 & 0.6 & -0.26 & -1.46 & 1.07 & -1.15 \\
\hline $14(\mathrm{M})$ & 6.67 & -3.53 & 7.67 & -0.46 & -1.92 & -0.24 & -2.62 & -1.32 \\
\hline $16(M)$ & 4.17 & -2.36 & 3.59 & -1.56 & 2.58 & -0.33 & -1.51 & 0.09 \\
\hline M mean & 0.55 & -0.72 & 1.84 & -0.82 & -0.97 & -0.31 & 0.08 & 0.03 \\
\hline \multirow[t]{2}{*}{ Total mean } & 0.20 & -0.26 & $1.10^{\star}$ & $-0.59^{\star}$ & $-1.25^{\star}$ & $-0.04^{\star}$ & -0.33 & -0.17 \\
\hline & \multicolumn{2}{|c|}{ ns } & \multicolumn{2}{|c|}{$p=0.0056$} & \multicolumn{2}{|c|}{$p=0.0053$} & \multicolumn{2}{|c|}{ ns } \\
\hline SD & 2.53 & 1.81 & 2.49 & 1.39 & 1.35 & 1.35 & 1.34 & 1.06 \\
\hline
\end{tabular}

ns = non-significant; ${ }^{*}$ statistically significant (according to statistical analysis with the Kruskal-Wallis test, $\mathrm{p}<0.05$ ).

Table 3 - Total mean, means for males and females, and standard deviations of the differences $T_{1}-T_{0}$ and $T_{2}-T_{1}$, for the measurements HRL-PR, HRL-Pg, HRL-B and VRL-ANS.

\begin{tabular}{|c|c|c|c|c|c|c|c|c|}
\hline \multirow[b]{2}{*}{ patient } & \multicolumn{2}{|c|}{ HRL-PR } & \multicolumn{2}{|c|}{ HRL-Pg } & \multicolumn{2}{|c|}{ HRL-B } & \multicolumn{2}{|c|}{ VRL-ANS } \\
\hline & $T_{1}-T_{0}$ & $T_{2}-T_{1}$ & $T_{1}-T_{0}$ & $T_{2}-T_{1}$ & $T_{1}-T_{0}$ & $\mathbf{T}_{2}-\mathrm{T}_{1}$ & $T_{1}-T_{0}$ & $T_{2}-T_{1}$ \\
\hline $2(F)$ & -0.9 & 0.17 & -1.22 & 0.04 & -0.46 & 0.54 & 3.9 & 0.56 \\
\hline $5(F)$ & 0.22 & -0.4 & -3.32 & 0 & -5.59 & 1.03 & 2 & -1.83 \\
\hline $7(F)$ & -0.16 & -2.71 & -2.24 & -4.7 & -0.52 & -2.57 & 1.82 & 0.71 \\
\hline $10(F)$ & -1.84 & 1.74 & -1.36 & 3.95 & -4.53 & 2.32 & 3.47 & 1.84 \\
\hline $15(F)$ & 2.53 & -2.32 & -7.03 & 1.03 & -11.23 & 0.94 & 4.39 & 1.5 \\
\hline $17(F)$ & -0.38 & -1.71 & -1.26 & 1.43 & -2.53 & -0.58 & 2.11 & -0.11 \\
\hline $18(F)$ & -0.26 & -0.54 & -0.03 & -1.65 & -2.89 & -2.14 & 7.53 & -2.48 \\
\hline $19(F)$ & -1.47 & -1.53 & 1.1 & -2 & 0.41 & 0.36 & -1.71 & 2.39 \\
\hline $20(F)$ & -0.34 & -1.71 & -12.84 & -1.22 & -11 & -0.54 & 6.32 & 2.13 \\
\hline F Mean & -0.29 & -1.0 & -3.13 & -0.35 & -4.26 & -0.07 & $3.31^{\star \star}$ & 0.52 \\
\hline $1(M)$ & -0.24 & -0.77 & -0.19 & -1.85 & -1.49 & 0.1 & 4.83 & -0.43 \\
\hline $3(M)$ & 2.03 & 0.84 & -0.63 & -1.03 & -0.63 & -1.03 & 9.64 & -1.67 \\
\hline $4(M)$ & -0.02 & 0.2 & -1.09 & -3.61 & -0.54 & -4.44 & 8.34 & 1.4 \\
\hline $6(M)$ & 7.49 & -2.46 & 3.68 & -0.67 & 2.95 & -1.37 & 12.59 & -3.98 \\
\hline $8(M)$ & 6.19 & -2.08 & -11.72 & -1.15 & -13.12 & -1.11 & 8.99 & 2.1 \\
\hline $9(M)$ & -3.37 & -0.95 & -0.28 & -2.3 & 0.67 & -0.87 & 8.45 & -3.29 \\
\hline $11(M)$ & 2.71 & -1.74 & -2.61 & -2.86 & -2.35 & -3.25 & 9.26 & -1.27 \\
\hline $12(\mathrm{M})$ & 3.72 & -0.17 & -8.99 & 3.49 & -4.47 & 1.45 & 9.48 & -1.85 \\
\hline $13(M)$ & 3.76 & -1.93 & -5.5 & 1.09 & -2.67 & -1.48 & 7.41 & 1.92 \\
\hline $14(M)$ & -2.87 & -0.57 & -1.28 & -1.85 & 0.62 & -0.34 & -0.18 & 0.14 \\
\hline $16(M)$ & -1.07 & 2.86 & -3.6 & -2.38 & -2.67 & -2.36 & 1.25 & -0.91 \\
\hline Mean M & 1.67 & -0.61 & -2.93 & -1.19 & -2.15 & -1.34 & $7.28^{\star \star}$ & -0.71 \\
\hline Total mean & $0.79^{\star}$ & $-0.79^{\star}$ & -3.02 & -0.81 & -3.10 & -0.77 & $5.49^{\star}$ & $-0.16^{\star}$ \\
\hline & \multicolumn{2}{|c|}{$p=0.0483$} & \multicolumn{2}{|c|}{ ns } & \multicolumn{2}{|c|}{ ns } & \multicolumn{2}{|c|}{$p=0.0001$} \\
\hline SD & 2.86 & 1.49 & 4.22 & 2.19 & 4.27 & 1.67 & 3.86 & 1.94 \\
\hline
\end{tabular}

$\mathrm{ns}=$ non-significant (according to statistical analysis with the Kruskal-Wallis test, $\mathrm{p}<0.05$ ). 
Table 4 - Total mean, means for males and females, and standard deviations of the differences $T_{1}-T_{0}$ and $T_{2}-T_{1}$, for the measurements $V R L-A$, VRL-PNS, VRL-Ar and VRL-PR.

\begin{tabular}{|c|c|c|c|c|c|c|c|c|}
\hline \multirow[b]{2}{*}{ Patient } & \multicolumn{2}{|c|}{ VRL-A } & \multicolumn{2}{|c|}{ VRL-PNS } & \multicolumn{2}{|c|}{ VRL-Ar } & \multicolumn{2}{|c|}{ VRL-PR } \\
\hline & $\mathrm{T}_{1}-\mathrm{T}_{0}$ & $T_{2}-T_{1}$ & $T_{1}-T_{0}$ & $T_{2}-T_{1}$ & $T_{1}-T_{0}$ & $\mathrm{~T}_{2}-\mathrm{T}_{1}$ & $\mathbf{T}_{1}-\mathbf{T}_{0}$ & $T_{2}-T_{1}$ \\
\hline $2(F)$ & 4.6 & -0.48 & 3.6 & -0.1 & 2.82 & -0.98 & 1.7 & -0.2 \\
\hline $5(F)$ & 4.54 & -2.26 & 5.7 & -1.38 & -0.75 & 0.73 & -0.38 & 0.23 \\
\hline $7(F)$ & 2.39 & -0.93 & 2.58 & 1.96 & -0.75 & 0.9 & 0.97 & -2.3 \\
\hline $10(F)$ & 3.81 & -0.28 & 3.17 & 0.23 & 1.35 & -0.53 & 2.23 & -0.78 \\
\hline $15(F)$ & 5.17 & 1.68 & 11.23 & -0.63 & 0.14 & 0 & 0.28 & -0.04 \\
\hline $17(F)$ & 4.92 & -0.16 & 4.46 & 0.69 & -0.28 & -0.03 & -0.73 & 1.24 \\
\hline $18(F)$ & 6.6 & -1.7 & 4.48 & -1.1 & 0.27 & -0.31 & -0.18 & -0.22 \\
\hline $19(F)$ & 0.93 & 0.23 & 1.55 & 0.92 & -0.27 & 2.1 & 5.65 & -7.19 \\
\hline $20(F)$ & 9.44 & 2.13 & 5.87 & 2.02 & 2.66 & 0.64 & -0.37 & 0.75 \\
\hline F Mean & 4.71 & -0.20 & 4.74 & 0.29 & 0.58 & 0.28 & 1.02 & -0.94 \\
\hline $1(M)$ & 3.23 & 2.1 & 5.69 & 0.82 & -0.53 & -0.52 & 2.84 & -2.38 \\
\hline $3(M)$ & 8.81 & 2.19 & 7.73 & 3.92 & 0.52 & -3.31 & 1.56 & -1.84 \\
\hline $4(M)$ & 6.96 & 1.4 & 6.44 & 1.08 & 0.12 & 0.16 & 0.04 & -2.54 \\
\hline $6(M)$ & 9.27 & -1.85 & 7.58 & 0.41 & 0.51 & -0.23 & 2 & -0.02 \\
\hline $8(M)$ & 10.48 & 3.04 & 7.07 & 1.6 & -0.21 & -0.99 & 2.83 & -3.78 \\
\hline $9(M)$ & 7.57 & -2.25 & 7.69 & -1.49 & -1.18 & 0.85 & -0.51 & 0.21 \\
\hline $11(\mathrm{M})$ & 11.16 & -1.86 & 10.22 & -0.59 & -2.16 & 0.03 & -1.95 & -1.04 \\
\hline $12(\mathrm{M})$ & 7.99 & -2.7 & 0.58 & -1.9 & 0.81 & 1.18 & 0.28 & 0.8 \\
\hline $13(M)$ & 7.68 & 2.12 & 6.91 & 0.6 & 1.2 & -0.63 & 1.98 & -1.98 \\
\hline $14(M)$ & -0.13 & -0.32 & 0.25 & -1.27 & 2.9 & 0.4 & 4.19 & -1.52 \\
\hline $16(M)$ & 1.64 & 1.93 & 4.08 & 0.93 & 0.36 & 0.1 & 2.42 & -3.09 \\
\hline M Mean & 6.78 & 0.34 & 5.84 & 0.37 & 0.21 & -0.27 & 1.42 & -1.56 \\
\hline \multirow[t]{2}{*}{ Total mean } & $5.85^{\star}$ & $0.10^{\star}$ & $5.34^{\star}$ & $0.34^{\star}$ & 0.38 & -0.02 & $1.24^{\star}$ & $-1.28^{\star}$ \\
\hline & \multicolumn{2}{|c|}{$p=0.0001$} & \multicolumn{2}{|c|}{$p=0.0001$} & \multicolumn{2}{|c|}{ ns } & \multicolumn{2}{|c|}{$p=0.0004$} \\
\hline SD & 3.25 & 1.84 & 2.93 & 1.44 & 1.32 & 1.09 & 1.85 & 1.97 \\
\hline
\end{tabular}

ns = non-significant. (According to statistical analysis with the Kruskal-Wallis test, $\mathrm{p}<0.05$ ).

Table 5 - Total mean, means for males and females, and standard deviations of the differences $T_{1}-T_{0}$ and $T_{2}-T_{1}$, for the measurements $V R L-P g$, VRL-B, Co-A and Co-Gn.

\begin{tabular}{|c|c|c|c|c|c|c|c|c|}
\hline & \multicolumn{2}{|c|}{ VRL-Pg } & \multicolumn{2}{|c|}{ VRL-B } & \multicolumn{2}{|c|}{ Co-A } & \multicolumn{2}{|c|}{ Co-Gn } \\
\hline Patient & $T_{1}-T_{0}$ & $T_{2}-T_{1}$ & $T_{1}-T_{0}$ & $T_{2}-T_{1}$ & $\mathrm{~T}_{1}-\mathrm{T}_{0}$ & $T_{2}-T_{1}$ & $\mathrm{~T}_{1}-\mathrm{T}_{0}$ & $T_{2}-T_{1}$ \\
\hline $2(F)$ & -8.94 & 0.7 & -7.81 & -0.18 & 7.52 & -0.31 & -4.72 & -0.47 \\
\hline $5(F)$ & -3.54 & -0.99 & -4.42 & -0.66 & 5.22 & -2.12 & -3.88 & -1.6 \\
\hline $7(F)$ & -8.67 & 4.55 & -9.63 & 4.21 & -0.02 & -0.67 & -9.61 & 1.7 \\
\hline $10(F)$ & 0.01 & -1.21 & -0.38 & -0.04 & 5.44 & -0.22 & -1.82 & 0.6 \\
\hline $15(F)$ & 0.23 & 0.43 & -1.36 & 0.96 & 4.94 & 2.6 & 0.79 & 0.22 \\
\hline $17(F)$ & 5.48 & 2.05 & -0.31 & 1.74 & 4.88 & -0.71 & 1.29 & 1.59 \\
\hline $18(F)$ & -0.87 & 2.33 & -0.94 & 1.87 & 7.75 & -2.03 & -0.55 & 0.97 \\
\hline $19(F)$ & -11.39 & 6.85 & -10.91 & 4.74 & 1.46 & 1.02 & -6.24 & 2.48 \\
\hline $20(F)$ & -6.97 & 2.48 & -6.17 & 2.54 & 13.15 & 2.66 & -9.79 & 3.85 \\
\hline F Mean & -3.85 & 1.91 & -4.66 & 1.69 & 5.59 & 0.02 & -3.84 & 1.04 \\
\hline $1(M)$ & -8.28 & 4.13 & -9 & 3.72 & 2.69 & 1.38 & -6.75 & -0.44 \\
\hline $3(M)$ & -4.28 & 2.52 & -4.42 & 2.3 & 9.49 & -0.99 & -3.68 & -2.94 \\
\hline $4(M)$ & -5.72 & 3.27 & -6.22 & 3.62 & 5.8 & 1.14 & -5.55 & 1.6 \\
\hline $6(M)$ & -9.93 & 0.91 & -9.31 & 2.01 & 8.49 & -1.51 & -4.7 & 1.14 \\
\hline $8(M)$ & 3.48 & 5.78 & 0.13 & 4.92 & 9.77 & 2.83 & -6.38 & 4.72 \\
\hline $9(M)$ & -0.64 & 0.95 & -0.43 & 0.34 & 3.98 & -0.52 & -1.56 & 0.29 \\
\hline $11(M)$ & 0.17 & 3.13 & 1.38 & 2.23 & 6.9 & 0.36 & -3.92 & 1.42 \\
\hline $12(\mathrm{M})$ & -7.5 & 1.05 & -7.77 & 0.8 & 7.93 & 1.27 & -7.17 & 2.92 \\
\hline $13(\mathrm{M})$ & -6.3 & 1.9 & -6.88 & 1.61 & 8.58 & 1.14 & -6.91 & -0.27 \\
\hline $14(M)$ & -20.27 & 3.81 & -19.84 & 3.91 & -0.64 & -0.77 & -9.07 & -1.43 \\
\hline $16(M)$ & -5.02 & 0.78 & -5.57 & 0.48 & 3.81 & 0.76 & -1.92 & 0.64 \\
\hline M Mean & -5.84 & 2.57 & -6.17 & 2.36 & 6.07 & 0.46 & -5.24 & 0.69 \\
\hline \multirow[t]{2}{*}{ Total mean } & $-4.95^{\star}$ & $2.27^{\star}$ & $-5.49^{\star}$ & $2.06^{\star}$ & $5.86^{\star}$ & $0.26^{\star}$ & $-4.61^{\star}$ & $0.85^{\star}$ \\
\hline & \multicolumn{2}{|c|}{$p=0.0001$} & \multicolumn{2}{|c|}{$p=0.0001$} & \multicolumn{2}{|c|}{$p=0.0001$} & \multicolumn{2}{|c|}{$p=0.0001$} \\
\hline SD & 5.85 & 2.08 & 5.08 & 1.69 & 3.43 & 1.49 & 3.26 & 1.84 \\
\hline
\end{tabular}

(Kruskal-Wallis' statistical analysis, $\mathrm{p}<0.05)$. 
Table 6 - Total mean, means for males and females, and standard deviations of the differences $T_{1}-T_{0}$ and $T_{2}-T_{1}$, for the measurements Nperp-A, Nperp-Pg and ANS-Me.

\begin{tabular}{|c|c|c|c|c|c|c|}
\hline \multirow[b]{2}{*}{ Patient } & \multicolumn{2}{|c|}{ Nperp-A } & \multicolumn{2}{|c|}{ Nperp-Pg } & \multicolumn{2}{|c|}{ ANS-Me } \\
\hline & $T_{1}-T_{0}$ & $\mathrm{~T}_{2}-\mathrm{T}_{1}$ & $\mathbf{T}_{1}-\mathbf{T}_{0}$ & $\mathrm{~T}_{2}-\mathrm{T}_{1}$ & $T_{1}-T_{0}$ & $T_{2}-T_{1}$ \\
\hline $2(F)$ & 7.54 & -0.81 & -3.8 & -0.6 & 0.41 & 2.08 \\
\hline $5(F)$ & 7.25 & -1.99 & -1.08 & 0.15 & -3.45 & -1.44 \\
\hline $7(F)$ & 5.16 & -2.06 & -4.57 & 1.99 & -0.49 & -2.45 \\
\hline $10(F)$ & 6.54 & -3.63 & 5.43 & -4.83 & -0.93 & 2.55 \\
\hline $15(F)$ & 6.67 & 3.48 & 1.8 & 2.42 & -0.49 & -4 \\
\hline $17(F)$ & 6.36 & -0.4 & 7.77 & 0.08 & -2 & 0.18 \\
\hline $18(F)$ & 5.79 & -1.44 & -1.85 & 3.54 & 0.1 & -1.35 \\
\hline $19(F)$ & 3.19 & -1.32 & -7.6 & 2.28 & -0.44 & -0.64 \\
\hline $20(F)$ & 8.7 & 0.39 & -8.24 & 2.09 & -11.79 & -1.86 \\
\hline F Mean & 6.35 & -0.86 & -1.35 & 0.79 & -2.12 & -0.77 \\
\hline $1(M)$ & 5.36 & -0.09 & -6.68 & -0.37 & 0.89 & -1.49 \\
\hline $3(M)$ & 14.23 & -1.19 & -5.72 & -3.05 & -0.02 & -0.6 \\
\hline $4(M)$ & 8.59 & -0.77 & -1.84 & 1.39 & -0.39 & -1.49 \\
\hline $6(M)$ & 8.58 & -0.61 & -10.03 & 2.23 & 9.52 & -3.9 \\
\hline $8(M)$ & 11.76 & -0.58 & 4.61 & 1.95 & -8.57 & -1.43 \\
\hline $9(M)$ & 6.64 & -1.45 & -0.66 & 1.5 & 1.46 & -1.19 \\
\hline $11(\mathrm{M})$ & 6.12 & -0.44 & -9.47 & 5.86 & 3.03 & -1.73 \\
\hline $12(\mathrm{M})$ & 12.04 & -0.55 & -0.89 & 3.32 & -4.37 & 0.89 \\
\hline $13(\mathrm{M})$ & 9.28 & -3.11 & -4.06 & -1.99 & -3.36 & -0.05 \\
\hline $14(M)$ & 5.36 & 1.21 & -4.72 & 5.53 & -5.3 & 2.23 \\
\hline $16(M)$ & 8.01 & -0.3 & 7.38 & 0.2 & -4.66 & -0.88 \\
\hline M Mean & 8.72 & -0.72 & -2.92 & 1.51 & -1.07 & -0.88 \\
\hline \multirow[t]{2}{*}{ Total mean } & $7.66^{\star}$ & $-0.78^{\star}$ & $-2.21^{\star}$ & $1.18^{\star}$ & -1.54 & -0.83 \\
\hline & \multicolumn{2}{|c|}{$p=0.0001$} & \multicolumn{2}{|c|}{$p=0.0102$} & \multicolumn{2}{|c|}{ ns } \\
\hline SD & 2.64 & 1.50 & 5.37 & 2.61 & 4.39 & 1.77 \\
\hline
\end{tabular}

ns $=$ non-significant (Kruskal-Wallis' statistical analysis, $\mathrm{p}<0.05)$.

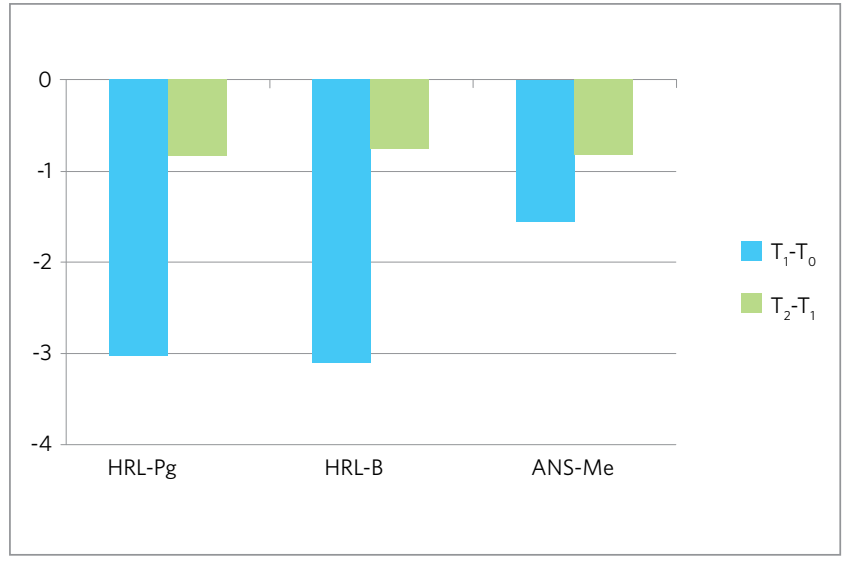

Figure 5 - Differences $T_{1}-T_{0}$ and $T_{1}-T_{2}$ of the three measurements related to the reduction in anterior and posterior facial height.

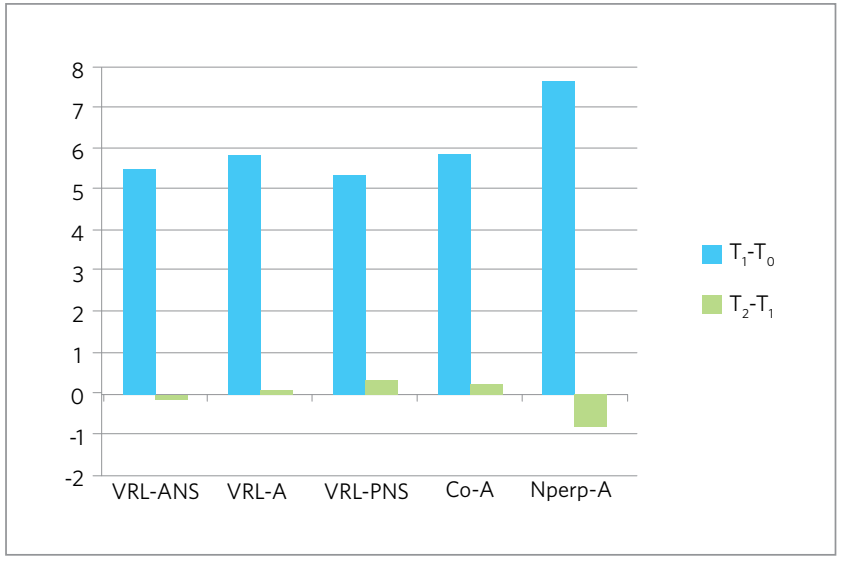

Figure 6 - Differences $T_{1}-T_{0}$ and $T_{2}-T_{1}$ of the five measurements related with the horizontal movement of the maxilla. 


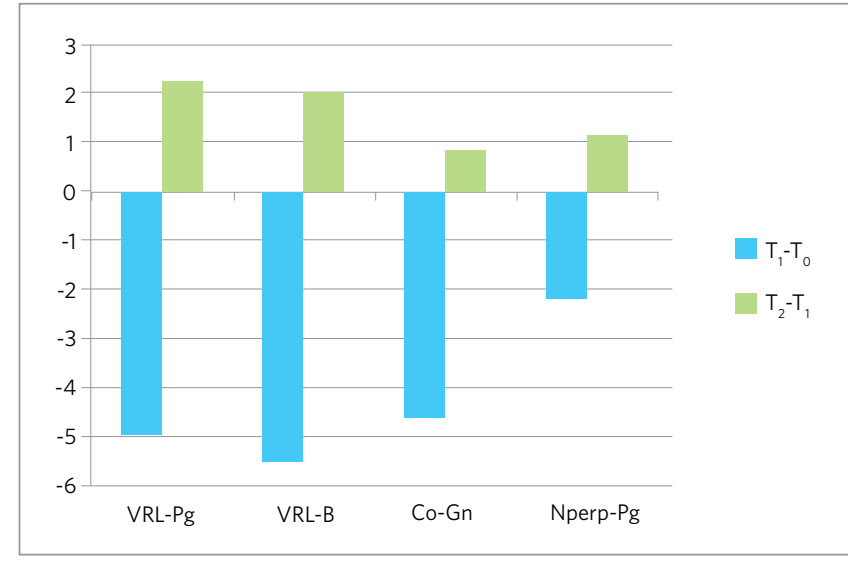

Figure 7 - Differences $T_{1}-T_{0}$ and $T_{2}-T_{1}$ of the five measurements related with the horizontal movement of the mandible.

The measurement HRL-Pg and HRL-B, which values represent the previous mandible alterations in the vertical direction, did not show statistically significant reductions from $\mathrm{T}_{0}$ to $\mathrm{T}_{1}$, but it showed a slight decrease of over $3 \mathrm{~mm}$ in the lower anterior face height due to surgical movement. From $\mathrm{T}_{1}$ to $\mathrm{T}_{2}$, all values were slightly reduced.

Analyzing the changes in the horizontal direction of the maxilla, it was found that the measurements VRL-ANS, VRL-A, VRL-PNS, Nperp-A e Co$A$, showed similar results, i.e., the differences $\mathrm{T}_{1}-\mathrm{T}_{0}$ and $\mathrm{T}_{2}-\mathrm{T}_{1}$ were statistically significant, representing a maxillary advancement in $\mathrm{T}_{1}$, and this movement was very stable.

Along with a similar result to that obtained in the vertical direction, the measurement VRL-Ar did not show statistically significant differences in the overall average, on patients from both genders.

The horizontal movement of the PR point, represented by the measurement VRL-PR, was significantly reduced in the overall averages for $\mathrm{T}_{1}$, returning to its initial value at $\mathrm{T}_{2}$. Analyzing the mandible alteration in the horizontal direction, it is observed in the overall average of measurement VRL-Pg a decrease of $4.95 \mathrm{~mm}$ at $\mathrm{T}_{1}$, and an increase of $2.27 \mathrm{~mm}$ in $\mathrm{T}_{2}$. There were no statistical differences on the stability between genders, and the results in $\mathrm{T}_{2}-\mathrm{T}_{1}$ often presented the same tendencies.

\section{DISCUSSION}

Some authors stated the need of more studies to assess the stability of the bimaxillary surgery using rigid internal fixation for the correction of Class III malocclusion, because there were only five works in the literature until 2004, a small number for comparisons $^{6,18}$ and several studies indicated the use of RIF because its advantages and, consequently, its in-

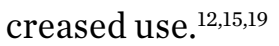

Patients show better treatment acceptance and comfort with the RIF, because without the need of using intermaxillary fixation, the recovery seems to be faster, as well as the performance of the orthodontist, speech pathologist and physiotherapist.

The skeletal relapse resulted from orthognathic surgical procedures occur in the first months after surgery. ${ }^{17}$ Most alterations in the soft tissue occurs within a year, but changes may occur up to 5 years after the surgery. ${ }^{11}$

The orthognathic surgery is a procedure where several factors can interfere on the success of the treatment, i.e., the stability. ${ }^{18}$ Several studies in literature show different results and indications, from surgical procedure to the type of bone fixation used. They also emphasized the importance of further research, preferably with specific samples, ie, with the same type of skeletal alterations, because according to the diagnosis, a specific type of surgery is indicated. The values found for the articulare point showed maintenance of the condyle position in the vertical direction, an important factor for the stability of surgical procedure and treatment.

From $\mathrm{T}_{1}$ to $\mathrm{T}_{2}$, all values of HRL-Pg and HRL-B showed a small reduction, and it was radiographically observed a better intercuspation, reducing the premature contacts in the post-operative period, along with the muscle adaptation to the new skeletal position, causing a counterclockwise rotation of the mandible, leaving a more anterior position, also evidenced by the posterior displacement of point $\mathrm{PR}$ at $\mathrm{T}_{1}$, and its return to baseline at $\mathrm{T}_{2}$. The measurement of ANS-Me also showed similar results, and they were different from those obtained in a study used as comparison, ${ }^{8}$ since the authors found no alteration in the vertical direction in the relation between maxilla and mandible (Table 3 and 6; Fig 5) .

The measurements, VRL-ANS, VRL-A, VRLPNS, Nperp-A e Co-A, showed similar results, ie, the differences $\mathrm{T}_{1}-\mathrm{T}_{0}$ and $\mathrm{T}_{2}-\mathrm{T}_{1}$ were statistically significant, representing a maxillary advancement in $\mathrm{T}_{1}$, and this movement was very stable, according to 
values assessed in $\mathrm{T}_{2}$, which compared to the results of other studies. ${ }^{6,714,19}$ A relapse of up to $2 \mathrm{~mm}$ in orthognathic surgery is clinically acceptable ${ }^{22}$ and no value in this study approached this value, proving the stability of maxillary advancement surgery (Tables 3, 4, 5 and 6; Fig 6).

A procedure can be classified as very stable when there is $90 \%$ of chance of alterations lower than 2 $\mathrm{mm}$ and barely any chance of more than $4 \mathrm{~mm}$ of post-surgical alteration. ${ }^{2}$ In this study 17 patients showed relapse lower than $2 \mathrm{~mm}$ according to analysis of obtained values in the measurements VRLANS, VRL-A, and Nperp-A, and 18 patients showed relapse lower than $2 \mathrm{~mm}$ for VRL-PNS and Co-A, and no patient had relapse greater than $4 \mathrm{~mm}$ on these five measurements. Although many patients undergo a maxilla advancement greater than $6 \mathrm{~mm}$, there was only one bone graft, and yet, it did not compromise the stability of the surgical moves, unlike those indicated by other authors. ${ }^{2425}$

With a similar result to that obtained on the vertical direction, the measurement VRL-Ar showed the maintenance of condylar position after surgery, an important factor for stability (Table 4).

The horizontal movement of the PR point, represented by the measurement VRL-PR, suffered a posterior dislocation at $\mathrm{T}_{1}$. In the sagittal osteotomy of the mandible, the ramus must remain in the same position, as long as the technique is performed correctly, occurring alteration only on the position of the body of mandible. As previously reported, with a better intercuspation and muscular adaptation after surgery, there was a mandibular counterclockwise turn in $\mathrm{T}_{2}$, and the PR point went back to its initial position (Table 4).

Now, analyzing the mandibular alterations in the horizontal direction, it is noticed on the overall average of measurement VRL-Pg a relapse of $45.85 \%$. The stability of point Pg was also analyzed in bimaxillary procedures with RIF by some authors, as it follows: To a setback of $5.43 \mathrm{~mm}$ there was a relapse of $2.90 \mathrm{~mm}$ or $53.4 \%,{ }^{9}$ in another study to a setback of $6,86 \mathrm{~mm}$ there was a relapse of $3.41 \mathrm{~mm}$ or $49.7 \%{ }^{6}$ and in another for a setback of $3.56 \mathrm{~mm}$ there was a relapse of $1.96 \mathrm{~mm}$ or $55 \%{ }^{19}$, similar results to the ones obtained in this study; it was obtained in another study ${ }^{21}$ a slightly higher result when compared to previous work, to a mandibular setback of $5.0 \mathrm{~mm}$ there was a relapse of $3.2 \mathrm{~mm}$, or $64 \%$; and in another research ${ }^{14}$ it was found a very low relapse, and a mandibular setback of $5.7 \mathrm{~mm}$ and relapse of $1.1 \mathrm{~mm}$ or $19.3 \%$.

From all 20 patients in the sample, four, or $20 \%$, had relapses greater than $4 \mathrm{~mm}$, seven, or $35 \%$, had relapses between 2 and $4 \mathrm{~mm}$, and nine, or $45 \%$, had relapse less than $2 \mathrm{~mm}$. The results were different when compared to another two studies, in $53 \%$ of patients in the first article there were relapses between 2 and $4 \mathrm{~mm}$, and in $11 \%$ of patients relapse greater than $4 \mathrm{~mm},{ }^{19}$ while in another, $27.3 \%$ of patients had relapses between 2 and $4 \mathrm{~mm}$, and $27.3 \%$ relapse greater than $4 \mathrm{~mm} .{ }^{9}$

Two considerations are worth to remember: The higher the mandibular setback, the greater the rotation of the proximal segment, therefore, it is more likely to relapse, this is due to changes in the spatial arrangement of muscles and soft tissues; ${ }^{9}$ and the other consideration is that the bimaxillary surgery presents less impact on the stretch of the soft tissues. ${ }^{21}$

The forward movement of the maxilla occurs due to anterior mandible rotation, because the condyles remain in the same cephalometric position, ${ }^{7}$ and this is verified in this study (Table 5; Fig 7).

The influence of the stretching muscles and the difficulty to adapt to the new position are mentioned in some studies as important factors on the relapse of the mandibular setback, because with mastication the mandibular ramus tends to return to its initial inclination. ${ }^{6,17,23}$ The performance of physiotherapists and speech therapists is crucial for muscle rehabilitation and post-surgical recovery.

There is greater influence of the amount of mandibular setback in bimaxillary surgeries, ${ }^{6}$ also reminding that relapse can be caused by the altered position of the condyle during surgery, less space for the tongue, and also the condylar growth. ${ }^{17}$

Patients with Class III malocclusion usually present maxillary deficiency, and a lower positioning of the tongue and, after surgery, with mandibular setback and maxillary advancement, there is the need of working the correct tongue positioning and its function to not interfere in the stability.

The relapse in mandibular setback is related to the greater influence of the mandibular muscles, and because it is a movable bone, there are more possibilities 
for errors in bone fixation and, consequently, for changing the position of the condyles. It must be emphasized that the bilateral sagittal osteotomy of the mandibular ramus is very suitable, because due to the separation of the ramus, the goal is to minimize the influence of muscle, since the surgical movement is performed on the body of the mandible.

Male patients showed a mean relapse of $44.00 \%$ in the measurement of VRL-Pg. Meanwhile, the female patients demonstrated a mean relapse of $42.54 \%$. These results were similar to those obtained in another study ${ }^{17}$ that also found slight relapse differences between genders.

Lower values were obtained for the measurement VRL-B. For the overall average, there was a relapse of $37.33 \%$, with males showing a mean relapse of $38.24 \%$ and $36.26 \%$ for the females.

As previously seen, according to the results obtained for the measurements HRL-Pg, HRL-B and ANS-Me, the horizontal relapse is related to mandibular rotation. Another important factor for the stability of mandibular surgery is the condylar adaptation, and remodeling may occur due to the new spatial arrangement of the musculature..$^{3,12}$

The size of the mandible, represented by the measurement Co-Gn, presented lower relapse values when compared to the measurement VRL-Pg and VRL-B, because the used reference was the point Co, and this measurement was influenced by mandibular setback, and not by the counterclockwise mandibular rotation occurred in $\mathrm{T}_{2}$.

After evaluating the results of Nperp-Pg for male patients, is esthetically acceptable a more protruded mandible when compared to the treatment planning for female patients. The mean value for females was $0.33 \mathrm{~mm}$ at $\mathrm{T}_{0} ;-1,01 \mathrm{~mm}$ at $\mathrm{T}_{1}$ and $-0.22 \mathrm{~mm}$ at $\mathrm{T}_{2}$. For male patients the mean value was $3.40 \mathrm{~mm}$ at $\mathrm{T}_{0} ; 0.49 \mathrm{~mm}$ at $\mathrm{T}_{1}$ and $2.00 \mathrm{~mm}$ at $\mathrm{T}_{2}$. For both genders these values were considered within the normal range $^{15}$ (Table 5; Fig 7).
After the analysis of the bimaxillary surgical treatment result in patients with Class III malocclusion, it was observed that the maxillary advancement procedure was very stable, but the mandibular setback may be influenced by factors such as muscle and cutaneous tissue and also because the bilateral sagittal osteotomy of the mandible is technically a more difficult procedure, presenting greater horizontal relapse. It also should be emphasized the contribution of the diminished anterior and posterior facial height in this result.

The orthodontic-surgical treatment, with improved techniques and a greater number of surgeons and medical centers, has become more accepted and accessible to the population, with clinical neat and stable results, reaching the patient's esthetic goals.

Although the most evident skeletal changes occur in surgery, surgical correction and stability, depends on a well defined treatment protocol, with interaction of several professionals.

\section{CONCLUSIONS}

In accordance with the analyzed sample, and the methodology used in this study, it can be concluded:

1. The Le Fort I Surgery for maxillary advancement with rigid internal fixation procedure was very stable in patients with Class III malocclusion treated with bimaxillary surgery of maxilla and mandible.

2. There was lack of stability of mandibular setback in patients with Class III malocclusion treated with bimaxillary surgery, due to the counterclockwise rotation of the mandible, causing an anterior displacement by better post-operative intercuspation and the patient's muscle adaptation to the new skeletal position.

3. Regarding stability there were no statistical differences between genders. 


\section{REFERENCES}

1. Ayoub AF, Mostafa YA, el-Mofty S. Soft tissue response to anterior maxillary osteotomy. Int J Adult Orthodon Orthognath Surg. 1991;6(3):183-90.

2. Bailey LJ, Cevidanes LH, Proffit WR. Stability and predictability of orthognathic surgery. Am J Orthod Dentofacial Orthop. 2004;126(3):273-7.

3. Bailey LT, Proffit WR, White RP Jr. Trends in surgical treatment of Class III skeletal relationships. Int J Adult Orthodon Orthognath Surg. 1995;10(2):108-18.

4. Bishara SE, Chu GW, Jakobsen JR. Stability of the Le Fort I one-piece maxillary osteotomy. Am J Orthod Dentofacial Orthop. 1988;94(3):184-200.

5. Burstone CJ, James RB, Legan H, Murphy GA, Norton LA. Cephalometrics for orthognathic surgery. J Oral Surg. 1978;36(4):269-77.

6. Politi M, Costa F, Cian R, Polini F, Robiony M. Stability of skeletal Class III malocclusion after combined maxillary and mandibular procedures. J Oral Maxillofac Surg. 2004;62(2):169-81.

7. Donatsky O, Bjørn-Jørgensen J, Holmqvist-Larsen M, Hillerup S. Computerized cephalometric evaluation of orthognathic surgical precision and stability in relation to maxillary superior repositioning combined with mandibular advancement or setback. J Oral Maxillofac Surg. 1997;55(10):1071-9; discussion 1079-80.

8. Enacar A, Taner T, Manav O. Effects of single or double-jaw surgery on vertical dimension in skeletal Class III patients. Int J Adult Orthodon Orthognath Surg. 2001;16(1):30-5

9. Franco JE, Van Sickels JE, Thrash WJ. Factors contributing to relapse in rigidly fixed mandibular setbacks. J Oral Maxillofac Surg. 1989;47(5):451-6.

10. Gassmann CJ, Nishioka GJ, Van Sickels JE, Thrash WJ. A lateral cephalometric analysis of nasal morphology following Le Fort I osteotomy applying photometric analysis techniques. J Oral Maxillofac Surg. 1989;47(9):926-30

11. Hack GA, de Mol van Otterloo JJ, Nanda R. Long-term stability and prediction of soft tissue changes after Le Fort I surgery. Am J Orthod Dentofacial Orthop. 1993;104(6):544-55

12. Helm G, Stepke MT. Maintenance of the preoperative condyle position in orthognathic surgery. J Craniomaxillofac Surg. 1997;25(1):34-8.

13. Houston WJB. The analysis of errors in orthodontic measurements. Am J Orthod. 1983;83(5):382-90.

14. Kwon TG, Mori Y, Minami K, Lee SH, Sakuda M. Stability of simultaneous maxillary and mandibular osteotomy for treatment of Class III malocclusion: an analysis of three-dimensional cephalograms. J Craniomaxillofac Surg. 2000;28(5):272-7.
15. Law JH, Rotskoff KS, Smith RJ. Stability following combined maxillary and mandibular osteotomies treated with rigid internal fixation. J Oral Maxillofac Surg. 1989:47(2):128-36

16. McNamara JA. A method of cephalometric evaluation. Am J Orthod. 1984;86(6):449-69.

17. Mobarak KA, Krogstad O, Espeland L, Lyberg T. Long-term stability of mandibular setback surgery: A follow-up of 80 bilateral sagittal split osteotomy patients. Int J Adult Orthodon Orthognath Surg. 2000;15(2):83-95

18. Mucedero M, Coviello A, Baccetti T, Franchi L, Cozza P. Stability factors after double-jaw surgery in Class III malocclusion. A systematic review. Angle Orthod. 2008;78(6):1141-52.

19. Politi M, Costa F, Cian R, Polini F, Robiony M. Stability of skeletal Class III malocclusion after combined maxillary and mandibular procedures: rigid internal fixation versus wire osteosynthesis of the mandible. J Oral Maxillofac Surg. 2004;62(2):169-81.

20. Proffit $W R$, Phillips $C$, Turvey TA. Stability following superior repositioning of the maxilla by Le Fort I osteotomy. Am J Orthod Dentofacial Orthop. 1987;92(2):151-61.

21. Proffit WR, Phillips C, Turvey TA. Stability after surgical-orthodontic corrective correction of skeletal Class III malocclusion. III. Combined maxillary and mandibular procedures. Int J Adult Orthodon Orthognath Surg. 1991;6(4):211-25.

22. Proffit WR, Turvey TA, Phillips C. Orthognathic surgery: A hierarchy of stability. Int J Adult Orthodon Orthognath Surg. 1996;11(3):191-204.

23. Sorokolit CA, Nanda RS. Assessment of the stability mandibular setback procedures with rigid fixation. J Oral Maxillofac Surg. 1990;48(8):817-22

24. Waite PD, Tejera TJ, Anucul B. The stability of maxillary advancement using Le Fort I osteotomy with and without genial bone grafting. Int J Oral Maxillofac Surg. 1996;25(4):264-67

25. Wardrop RW, Wolford LM. Maxillary stability following downgraft and/or advancement procedures with stabilization using rigid fixation and porous block hydroxyapatite implants. J Oral Maxillofac Surg. 1989;47(4):336-42.

26. Wang XX, Zhang J, Zhang WJ, Li N, Shi HT. A stability study of hard tissue changes in patients with skeletal Class III malocclusion after orthodontic-orthognathic treatments. Hua Xi Kou Qiang Yi Xue Za Zhi. 2009;27(1):60-3.

27. Welch TB. Stability in the correction of dentofacial deformities: a comprehensive review. J Oral Maxillofac Surg. 1989;47(11):1142-9. 